\title{
EFEKTIVITAS SPEKTROFOTOMETER EDUKASI SEBAGAI MEDIA PEMBELAJARAN ANALISIS INSTRUMEN DI SEKOLAH MENENGAH KEJURUAN (SMK) ANALISIS KESEHATAN DAN ANALIS KIMIA
}

\section{EFFECTIVENESS OF EDUCATION SPECTROFOTOMETERS \\ AS LEARNING MEDIA INSTRUMENT ANALYSISIN MIDDLE VOCATIONAL SCHOOL (SMK)HEALTH ANALYSIS AND CHEMICAL ANALYSIS}

\author{
Fifit Astuti*, Yohan \\ Program Studi Teknik Mesin Fakultas Teknik Universitas Pamulang \\ J1. Surya Kencana No.1, Pamulang Barat Kecamatan Pamulang Kota Tangerang Selatan, Banten 15417 \\ dosen01140@unpam.ac.id
}

\begin{abstract}
Learning in Vocational High Schools (SMK) oriented to graduates has special expertise and is able to compete in the world of work. To achieve these objectives, learning in SMKs particularly instrument analysis must be supported by learning media. A welldesigned learning media will greatly assist students in digesting and understanding the material. Spectrophotometer is a new innovation that was developed to overcome the problem of the limited learning media for instrument analysis in schools. Therefore in this study aims to determine the effectiveness of spectrophotometer learning media. This effectiveness can be seen from the differences in learning achievement of instrument analysis students before and after learning with educational specrophotometers. This research uses quantitative research methods with Quasi Experimental Design methodology of Time Series Design type. The instruments used in this study consisted of multiple choice questions and description questions. Data were analyzed using prerequisite test analysis and hypothesis test analysis with Paired Sample T Test technique. The results showed that there were differences in the learning achievement of chemical analysis instruments before and after learning with educational spectrophotometer media that was 33.48. This is reinforced by the average empirical achievement of 39.46 and the average empirical posttest of 70.49. Based on these results it can be said that the developed spectrophotometer media has been effective.
\end{abstract}

Keywords: spectophotometer, learning achievement, chemical analysis.

\begin{abstract}
ABSTRAK
Pembelajaran di Sekolah Menengah Kejuruan (SMK) berorienasi pada lulusannya mempunyai keahlian khusus dan mampu bersaing di dunia pekerjaan. Untuk mencapai tujuan tersebut, pembelajaran di SMK khususnya analisis insrument harus didukung dengan media pembelajaran. Media pembelajaran yang dirancang secara baik akan sangat membantu siswa dalam mencerna dan memahami materi. Spektrofotometer merupakan inovasi baru yang dikembangkan untuk mengatasi permasalahan terbatasnya media pembelajaran analisis instrumen di sekolah. Oleh karena itu pada penelitian ini bertujuan untuk mengetahui efektivitas media pembelajaran spektrofotometer.
\end{abstract}


Efektivitas ini dilihat dari perbedaan prestasi belajar analisis instrument siswa sebelum dan sesudah pembelajaran dengan spekrofotometer edukasi. Penelitian ini menggunakan metode penelitian kuantitatif dengan metodelogi Quasi Experimental Design tipe Time Series Design. Intrumen yang digunakan pada penelitian ini terdiri soal pilihan ganda dan soal uraian. Data dianalisis menggunakan analisis uji prasyarat dan analisis uji hipotesis dengan teknik Paired Sample T Test. Hasil penelitian menunjukan bahwa terdapat perbedaan prestasi belajar kimia analisis instrumen sebelum dan sesudah pembelajaran dengan media spektrofotometer edukasi yaitu sebesar 33,48. Hal ini diperkuat dengan rata-rata prestasi empiris sebesar 39,46 dan rata-rata posttest empiris sebesar 70,49. Berdasarkan hasil tersebut dapat dikatakan bahwa media spektrofotometer yang dikembangkan ini sudah efektif.

\section{Kata kunci: Spekrofotometer edukasi, prestasi belajar, kimia analisis}

\section{PENDAHULUAN}

Sekolah Menengah Kejuruan (SMK) kimia analisis merupakan salah satu sekolah SMK yang berorientasi pada lulusannya mempunyai keahlian khusus menganalisa bahan-bahan kimia dan siap untuk berkerja. Untuk mencapai tujuan tersebut, pembelajaran di SMK analisis sebagain besar harus berupa eksperimen karena dengan merancang penelitian di laboratorium membantu siswa berfikir lebih mandiri [1]. Hal ini sesuai dengan piramida pembelajaran Edgar Dale dengan pendidikan yang berbasis eksperimen atau melakukan hal yang nyata dapat meningkatkan pemahaman dan daya ingat sekitar 90\% [2]. Dengan sistem pembelajaran yang berbasis eksperimen ini dapat membantu mewujudkan pengembangan ilmu pengetahuan dan teknologi dalam menghadapi persaingan Masyarakat Ekonomi Asean (MEA).

Spektrofotometer merupakan salah satu instrumen penting di laboratorium untuk analisis kimia baik secara kualitatif maupun kuantitatif. Namun di sebagian besar Sekolah Menengah Kejuruan (SMK) analisis kesehatan/kimia analisis belum memiliki alat ini. Hal ini disebabkan karena spektrofotometer harganya mahal. Untuk pemenuhan kebututuhan alat ini, negara Indonesia masih mengimport dari negara lain.

Yohan dan Fifit telah berhasil membuat spektrofotometer edukasi berdasarkan arduino uno dengan menggunakan sumber cahaya LED dengan panjang gelombang 402$632 \mathrm{~nm}$ [5]. Oleh karena itu, pada penelitian ini akan dilakukan aplikasi alat ini sebagai media pembelajaran di SMK analis kimia pada materi analisis kimia instrumen. Tujuan khusus penelitian ini adalah mengetahui tingkat efektivitas spektrofotometer dalam pembelajaran analisis kimia instrumen. Harapannya dengan penelitian ini, bagi siswa SMK lebih mudah memahami materi analisis kimia instrumen khususnya 
spektrofotometer UV-Vis, dapat mengoperasikan alat ini dan mempunyai banyak pengalaman sehingga siap untuk memasuki dunia kerja. Bagi pendidik terpenuhinya media pembelajaran yang efektif dengan harga terjangkau sehingga memudahkan sekolah sekolah dalam pemenuhan alat laboratorium.

\section{METODOLOGI}

Metode penelitian yang digunakan adalah penelitian kuantitatif dengan metodelogi Quasi Experimental Design tipe Time Series Design. Metodelogi ini tanpa menggunakan kelas eksperimen dan kontrol, tetapi hanya melakukan pretest, dan melakukan posttest, kemudian dibandingkan. Untuk melakukan metode quasi eksperimen, maka peneliti desain penelitian seperti pada Gambar 3.1.

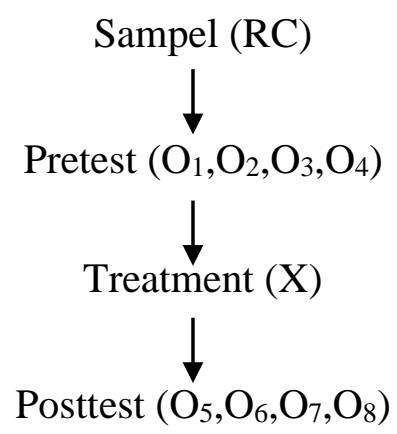

\section{Gambar 1.Time Series Design}

Keterangan :

$\mathrm{O}_{1}, \mathrm{O}_{2}, \mathrm{O}_{3}, \mathrm{O}_{4}=$ kondisi sebelum diberi perlakuan

$\mathrm{X} \quad=$ pemberian perlakuan

$\mathrm{O}_{5}, \mathrm{O}_{6}, \mathrm{O}_{7}, \mathrm{O}_{8}=$ Kondisi setelah perlakuan

Sedangkan diagram penelitian spektrofotometer ini seperti pada Gambar 3.2.

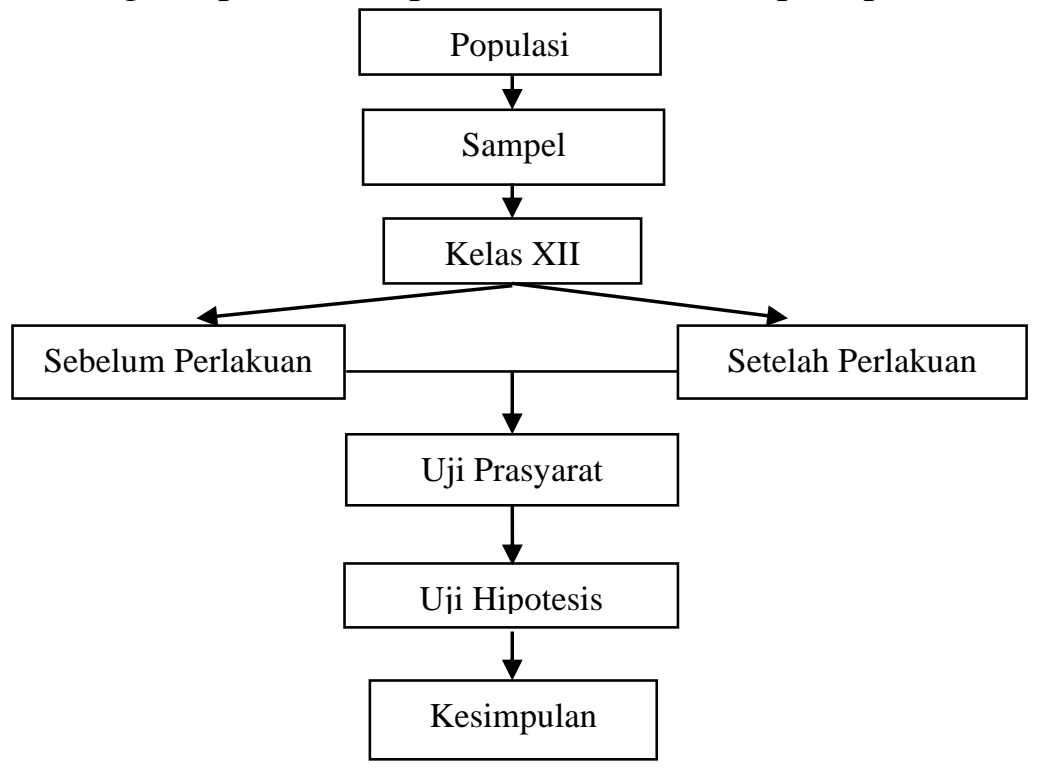




\section{Gambar 2. Alur Penelitian Spektrofotometer}

Populasi pada penelitian ini adalah siswa kelas XI, XII SMK Kota Tangerang Selatan jurusan analisis kesehatan dan analisis kimia. Penentuan sampel pada penelitian ini menggunakan teknik simpel random sampling yaitu cara penentuan sampel dengan cara acak tanpa memperhatikan strata. Teknik ini digunakan karena dianggap populasi memiliki kemampuan yang homogen. Sampel pada penelitian ini adalah siswa-siswa kelas XII SMK Sasmita Jaya 1.

Teknik pengumpulan data yang digunakan adalah non tes dan tes. Alat pengumpulan data berupa soal pilihan ganda dan soal uraian. Berikut disajikan Tabel 1 tentang teknik dan alat pengumpulan data pada penelitian ini.

Tabel 1. Teknik dan Alat Pengumpulan Data

\begin{tabular}{|c|l|l|l|l|}
\hline No & Nama Data & \multicolumn{1}{|c|}{ Tujuan } & \multicolumn{1}{c|}{ Teknik } & \multicolumn{1}{c|}{ Alat } \\
\hline 1 & $\begin{array}{l}\text { Keadaan } \\
\text { awal proses } \\
\text { pembelajaran }\end{array}$ & $\begin{array}{l}\text { Mengetahui keadaan } \\
\text { awal proses } \\
\text { pembelajaran }\end{array}$ & Non Tes & $\begin{array}{l}\text { Lembar } \\
\text { Observasi } \\
\text { Tidak terstruktur }\end{array}$ \\
\hline 2 & $\begin{array}{l}\text { Prestasi } \\
\text { belajar siswa }\end{array}$ & $\begin{array}{l}\text { Mengetahui data } \\
\text { prestasi belajar siswa } \\
\text { sebelum dan sesudah } \\
\text { diberi perlakuan }\end{array}$ & Tes & $\begin{array}{l}\text { Soal pilihan } \\
\text { ganda dan } \\
\text { uraian }\end{array}$ \\
\hline
\end{tabular}

Teknik analisis data yang digunakan yaitu analisis uji prasyarat dan analisis uji hipotesis dengan teknik Paired Sample T Test. Uji prasyarat yan digunakan untuk melakukan uji hipotesis yaitu uji normalitas sebagai uji prasyarat untuk melakukan uji paired sample test $t$ test dengan taraf kesalahan 5\%. Teknik ini digunakan untuk mengetahui perbedaan prestasi belajar sebelum dan sesudah diberi perlakuan. Berikut langkah-langkah uji analisisnya:

1. Rumuskan hipotesis

2. Rancangan analisis

3. Analisis sampel dengan software SPSS

a. Output Paired Sample Test

Apabila nilai sig > 0,05 (5\%), artinya $\mathrm{H}_{\mathrm{o}}$ diterima dan $\mathrm{H}_{1}$ ditolak.

Apabila nilai sig $<0,05(5 \%)$, artinya $\mathrm{H}_{\mathrm{o}}$ ditolak dan $\mathrm{H}_{1}$ diterima.

b. Output Paired Sample Statistics 


\section{PEMBAHASAN}

Efektvitas merupakan faktor terpenting dalam suatu proses pembelajaran. Salah satu kriteria pembelajaran dikatakan efektif jika skor rata-rata hasil belajar siswa lebih atau sama dengan nilai KKM yaitu 70. Perbedaan prestasi belajar analisis instrumen siswa sebelum dan sesudah diajar dengan bantuan media spektrofotometer edukasi dapat dilihat pada tabel 3 dibawah ini

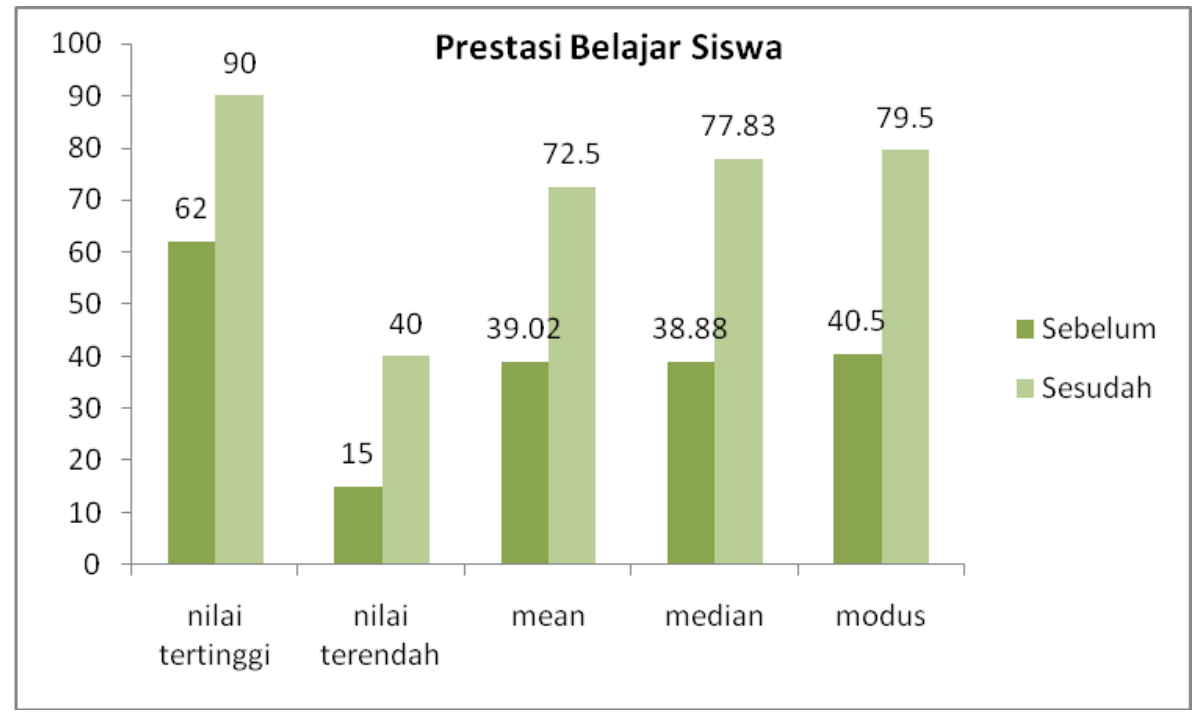

\section{Gambar 3. Grafik Prestasi Belajar Siswa}

Berdasarkan Gambar 3 di atas dapat dilihat bahwa nilai prestasi analisis instrumen tertinggi setelah treatment yaitu 90, nilai terendah yaitu 40. Dengan nilai rata-rata sebesar 72,50 yaitu diatas nilai KKM kimia analisis instrumen di SMK yaitu 65.

Hasil penelitian yang diperoleh dilakukan uji hipotesis yang pertama menggunakan paired sampel t test. Sebelum melakukan uji tersebut, data sampel harus memenuhi kriteria yaitu berdistribusi normal. Berikut ini hasil analisis tersebut.

1. Uji Prasyarat (Uji Normalitas)

$\mathrm{H}_{\mathrm{o}} \quad$ : data sampel berdistribusi normal

$\mathrm{H}_{1} \quad$ : data sampel tidak berdistribusi normal

\begin{tabular}{lcccccc}
\hline \multicolumn{7}{c}{ Tests of Normality } \\
\hline \multicolumn{7}{c}{ Kolmogorov-Smirnov } \\
& Statistic & Df & Sig. & Statistic & Df & Sig. \\
\hline Selisih & .104 & 65 & .079 & .962 & 65 & .046 \\
\hline
\end{tabular}


Lilliefors Significance Correction

Gambar 4. Ouput Test of Normality Data Prestasi Siswa

\begin{tabular}{|c|c|c|c|c|c|}
\hline \multicolumn{6}{|c|}{ Paired Samples Statistics } \\
\hline & & Mean & & Std. Deviation & Std. Error Mean \\
\hline Pair & Pretest & 39.46 & 65 & 10.890 & 1.351 \\
\hline 1 & Posttest & 70.49 & 65 & 11.473 & 1.423 \\
\hline
\end{tabular}

Berdasarkan output tests of normality pada Gambar 4 di atas, diperoleh nilai Smirnov 0,079>0,05, maka Ho diterima. Jadi dapat disimpulkan bahwa data sampel prestasi berdistribusi normal dan dapat dilanjutkan ke uji Paired Sampel T Test.

2. Uji Hipotesis (Paired Sampel t Test)

\begin{tabular}{|c|c|c|c|c|c|c|c|c|c|}
\hline \multicolumn{10}{|c|}{ Paired Samples Test } \\
\hline & & \multicolumn{5}{|c|}{ Paired Differences } & \multirow[t]{5}{*}{$\mathrm{t}$} & \multirow[t]{5}{*}{ df } & \multirow{5}{*}{$\begin{array}{l}\text { Sig. } \\
(2- \\
\text { tailed) }\end{array}$} \\
\hline & & \multirow[t]{4}{*}{ Mean } & \multirow{4}{*}{$\begin{array}{c}\text { Std. } \\
\text { Deviati } \\
\text { on }\end{array}$} & \multirow{4}{*}{$\begin{array}{l}\text { Std. } \\
\text { Error } \\
\text { Mean }\end{array}$} & \multirow{3}{*}{\multicolumn{2}{|c|}{$\begin{array}{c}\text { 95\% Confidence } \\
\text { Interval of the } \\
\text { Difference }\end{array}$}} & & & \\
\hline & & & & & & & & & \\
\hline & & & & & & & & & \\
\hline & & & & & Lower & Upper & & & \\
\hline Pair & Pretest & -31.031 & 11.893 & 1.475 & -33.978 & -28.084 & -21.036 & 64 & .000 \\
\hline \multirow[t]{2}{*}{1} & - & & & & & & & & \\
\hline & Posttest & & & & & & & & \\
\hline
\end{tabular}

\section{Gambar 5. Output Uji Hipotesis Data Prestasi Siswa}

$\mathrm{H}_{0(1)}$ : tidak terdapat perbedaan prestasi belajar analisis instrumen siswa sebelum dan sesudah diajar dengan media analisis instrumen.

$\mathrm{H}_{1(1)}$ : terdapat perbedaan prestasi belajar analisis instrumen siswa sebelum dan sesudah diajar dengan media analisis instrumen.

$\mathrm{H}_{0(1)}$ : tidak terdapat perbedaan prestasi belajar analisis instrumen siswa sebelum dan sesudah diajar dengan media analisis instrumen.

$\mathrm{H}_{1(1)}$ : terdapat perbedaan prestasi belajar analisis instrumen siswa sebelum dan sesudah diajar dengan media analisis instrumen.

Berdasarkan output paired sample test diperoleh nilai sig 0,000<0,05, maka $\mathrm{H}_{1}$ diterima. Berdasarkan output paired sample statistics diperoleh rata-rata prestasi pretest empiris sebesar 39,46, rata-rata prestasi posttest empiris sebesar 70,49 jadi bahwa terdapat perbedaan prestasi belajar analisis instrumen siswa sebelum dan sesudah diajar 
dengan media spektrofotometer edukasi. Hal ini diperkuat dengan rata-rata prestasi pretest empiris sebesar 39,46 dan rata-rata prestasi postets empiris sebesar 70,49.

Perbedaan prestasi diatas, disebabkan oleh proses pembelajaran sebelumnya hanya sebatas transfer pengetahuan saja, hanya mencatat materi kemudian dijelaskan dengan teknik ceramah saja, dan kemudian diberi contoh soal. Teknik tersebut harusnya divariasikan dengan strategi-strategi pembelajaran yang mengaktifkan siswa, agar pengetahuan yang diperoleh tidak sebatas mengingat, melainkan dapat dipahami siswa.

Prestasi siswa setelah diberi pembelajaran dengan media spektrofotometer meningkat sebesar 33,48. Hal tersebut dikarenakan proses pembelajaran dengan spektrofotometer siswa melihat langsung bagian-bagian apa saja yang ada pada spektrofotometer, bagaimana melakukan uji analisa suatu bahan dan prinsip kerja alat tersebut. Dengan pembelajaran seperti ini membantu siswa untuk lebih mudah memahami dengan jelas materi yang disampaikan. Perhatian siswa lebih mudah dipusatkan kepada proses belajar dan tidak tertuju yang lain sebab siswa memperoleh persepsi yang jelas dari hasil pengamatannya. Pada pembelajaran ini siswa turut aktif melakukan demontrasi uji kualitatif dengan spektrofotometer sehingga siswa memperoleh pengalaman praktek dan ketrampilan. Menurut kerucut pengalaman Edgar Dale [2] semakin konkret mempelajari bahan pengajaran akan memperoleh semakin banyak pengalaman yang diperolehnya.

\section{SIMPULAN}

Berdasarkan penelitian ini dapat simpulkan bahwa media pembelajaran spektrofotometer edukasi efektif digunakan dalam pembelajaran kimia analisis instrumen. Hal ini disebabkan karena terdapat perbedaan prestasi belajar kimia analisis instrumen sebelum dan sesudah pembelajaran dengan media spektrofotometer edukasi yaitu sebesar 33,48. Hal ini diperkuat dengan rata-rata prestasi empiris sebesar 39,46 dan rata-rata posttest empiris sebesar 70,49.

\section{DAFTAR PUSTAKA}

Walt Erhardt. 2007. Instrumental Analysis in the High School Classroom: UV-Vis Spectroscopy. J.Chem. Educ.84 (6). pp.1024.
Pastore,
Raymond
S
2016.Dale'S
Cone
of
Experience 
www.teacherworld.com/potdale.htm1 diakses tanggal 25 September 2018,

Elise, K.G., Morgan, H. T., Adam, W.S. 2016. Teaching UV-Vis Spectroscopy with a 3D-Printable Smartphone Spectrophotometer. J.Chem. Educ.93(1). pp.141-151.

Yohan., Fifit. 2016.Perancangan spektrofotometri sederhana berdasarkan arduino UNO. Jurnal proses produksi teknik kimia unpam.ISSN 25408062: Volume II.

Yohan., Fifit., 2017. Pembuatan Spektrofotometer Edukasi Dalam upaya peningkatan kualitas laboratorium Sekolah Menengah Kejuruan Analisis Kesehatan dan Anakisis Kimia

Caulcutt, R.., Boddy, R. 1983. Statistics for Analitical Chemsist. Chapman and Hall. London. ISBN: $041223730 \mathrm{X}$.

Sadiman, dkk.2014. Pentingnya Media Pembelajaran, Jakarta

Daniel, R. A., Michael, A.T., Davis, H.F. 2012.A Low-Cost Quantitative Absorption Spectrophotometer. J.Chem. Educ.89. pp.1432-1435.

Yeh T.S., Tseng S.S., 2013. A Low Cost LED Based Spectrometer. Journal of The Chinese Chemical Society

Solvason, G.,. 2015.Master of Science Thesis, Mechanical Engineering, Reykajavic University, Iceland,.

Gong,W., Mowlem, M., Kraft, M., Morgan, H. 2009.A simple low-cost double beam spectrophotometer for colorimetric detection of nitrite in sea water. ISSE sensor jounal:7 (862-869). 